\title{
Action spectrum for the effects of UV radiation on photosynthesis in the hermatypic coral Pocillopora damicornis
}

\author{
Michael P. Lesser ${ }^{1, *}$, Sarah Lewis ${ }^{2}$ \\ ${ }^{1}$ Department of Zoology and Center for Marine Biology, University of New Hampshire, Durham, New Hampshire 03824, USA \\ ${ }^{2}$ Institute of Ecology, University of Georgia, Athens, Georgia 30602, USA
}

\begin{abstract}
Colonies of the hermatypic coral Pocillopora damicornis were collected from the shallow reefs of Kaneohe Bay, Hawaii, to assess the wavelength-dependent effects of ultraviolet (UV) radiation on photosynthesis. Measurements of photosynthesis and respiration were made while corals were exposed to different UV irradiances, keeping visible radiation constant, using long-band pass filters. A differential action spectrum (biological weighting function) for the inhibition of photosynthesis by UV radiation was then determined for $P$. damicornis. The action spectrum revealed an increase in the wavelength-dependent effects of UV radiation on photosynthesis between 290 and $310 \mathrm{~nm}$ that is greater than those increases reported for action spectra on natural assemblages and unialgal cultures of marine microalgae. The greater effect at these wavelengths is a result of the high biologically effective doses of UV radiation experienced by these corals on shallow reefs, and the decrease in the absorbance of UV radiation by UV absorbing compounds found in the host tissues and algal symbionts between 290 and $310 \mathrm{~nm}$. The irradiances of wavelengths in the region between 290 and $310 \mathrm{~nm}$ are those which will increase in the event of any decrease in stratospheric ozone over equatorial regions. If the observed sensitivity of $P$. damicornis in this spectral region is common in other species, it may have important consequences for growth, reproduction, and occurrence of the bleaching phenomenon for shallow water corals
\end{abstract}

KEY WORDS: UV radiation $\cdot$ Corals $\cdot$ Action spectrum $\cdot$ Photosynthesis

\section{INTRODUCTION}

The decrease of stratospheric ozone from anthropogenic inputs of chlorinated fluorocarbons has resulted in an increase in the amount of harmful UV-B $(290$ to $320 \mathrm{~nm})$ reaching the sea surface in northern and southern latitudes. The natural concentration of ozone, however, is known to be thinner near the equator (Cutchis 1982) such that tropical ecosystems have a long evolutionary history of exposure to greater fluxes of UV radiation than those measured at high latitudes (Green et al. 1974, Frederick et al. 1989), and recent data describing global decreases in stratospheric ozone, with calculated increases in UV-B, did show a

·E-mail: mpl@christa.unh.edu trend of ozone loss over equatorial regions (Madronich 1992). Owing to the high transparency of tropical ocean waters, UV radiation penetrates to considerable (>20 m) depths (Jerlov 1950, Smith \& Baker 1979, Fleischman 1989). These wavelengths are known to have a detrimental effect on photosynthesis and growth in corals (Glynn et al. 1992, Shick et al. 1995) and zooxanthellae (Jokiel \& York 1982, 1984, Lesser \& Shick 1989), and on the survival of coral reef epifauna (Jokiel 1980, Siebeck 1988). Ultraviolet radiation has also been implicated as one cause of bleaching in corals and other symbiotic cnidarians (Lesser et al. 1990, Glynn et al. 1992, Gleason \& Wellington 1993)

It is widely assumed that corals are protected against the deleterious effects of UV radiation by UV-absorbing compounds, known as mycosporine-like amino acids (MAAs), which act as a broad-band filter when 
host tissues contain several MAAs of differing absorption maxima (Dunlap \& Chalker 1986, Stochaj et al. 1994, Shick et al. 1995). The concentrations of these compounds vary inversely with depth (Dunlap et al. 1986, Shick et al. 1995, Lesser unpubl.), and have also been shown to increase in concentration in response to transplanting or experimental altering of the exposure of corals to higher UV irradiances (Jokiel \& York 1982, Gleason 1993, Kinzie 1993)

Shallow-water corals are generally more resistant to UV exposure than are conspecifics from deeper water (Siebeck 1988). Gleason (1993) reported a correlation in the bathymetric distribution of certain morphotypes of Porites astreoides with their concentration of MAAs such that the effects of UV radiation on skeletal growth rates, and in hospite mitotic indices of zooxanthellae, were decreased in shallow water morphotypes with increased concentrations of MAAs. Additionally, changes in the photosynthetic performance of corals have been observed under conditions where exposure to UV radiation was experimentally manipulated (Kinzie 1993, Shick et al. 1995).

We presently do not know the wavelength-dependent effects of UV radiation for essential physiological functions in corals, although an action spectrum by Halldal (1968) on isolated zooxanthellae from Favia pallida suggested that UV radiation inhibits photosynthesis. These findings are also supported by action spectra for photoinhibition by UV radiation in cultured zooxanthellae of Aiptasia pallida (Lesser 1996b). Action spectra and accurate radiometry are essential for making predictions through modeling (Smith et al. 1980, Caldwell et al. 1986, Coohill 1989) and will be especially so in the event of continued changes in the rate and geographic extent of ozone depletion. Here, we describe an action spectrum for the inhibition of photosynthesis by UV radiation in the hermatypic coral Pocillopora damicornis from Hawaii.

\section{MATERIALS AND METHODS}

Samples. Samples of Pocillopora damicornis were collected at the Hawaii Institute of Marine Biology (HIMB), Kaneohe Bay, during July 1994. Samples were collected from a windward reef ('Point Reef') site by snorkeling. All samples were collected in $1.0 \mathrm{~m}$ of water and ranged in size from 6 to $8 \mathrm{~cm}$ colony height. Coral samples were brought back to the HIMB laboratory, cleaned of epibionts, and held for 24 to $48 \mathrm{~h}$ in flowing seawater tanks under full ambient solar irradiation until deployment in an underwater respirometer.

Oxygen flux data. Colonies of Pocillopra damicornis were placed in a self-contained, multichambered, underwater respirometer as described in detail by
Porter et al. (1984) at $1.0 \mathrm{~m}$ depth for 24 to $36 \mathrm{~h}$ to obtain oxygen flux and underwater irradiance data. Briefly, the chambers have a volume of 21 and are approximately $15 \mathrm{~cm}$ in diameter. They are made of cylindrical Plexiglas (50\% cutoff at $385 \mathrm{~nm}$ ) with UV transparent ( $90 \%$ transmission of ambient solar radiation) quartz lids. All chambers were constantly stirred and flushed at $30 \mathrm{~min}$ intervals to prevent supersaturation of the seawater with oxygen during the day. Changes in oxygen concentration were measured using calibrated YSI Model 57 polarographic electrodes. Data were collected and stored, then downloaded to a computer and converted to oxygen concentrations and fluxes. The incident photosynthetically active radiation (PAR; 400 to $700 \mathrm{~nm}$ ) was recorded using an external $4 \pi$ spherical quantum sensor simultaneously with the oxygen flux data. Temperatures within the chambers ranged from 26 to $28^{\circ} \mathrm{C}$ during the day. Photosynthesis and respiration were normalized to colony chlorophyll a (chl a) content as determined immediately after removal from the respirometer by covering each colony overnight with $90 \%$ acetone 2 or 3 successive times at $4^{\circ} \mathrm{C}$, recording the total volume of acetone used, and combining all extracts. The equations of Jeffrey \& Humphrey (1975) were then used to calculate the concentrations of chl a.

Spectroradiometery. Spectral data (300 to $700 \mathrm{~nm}$ ) were recorded using a LiCor LI-1800UW scanning spectroradiometer (LiCor, Lincoln, NE, USA) throughout the $36 \mathrm{~h}$ incubation period. The reported data are maximum downwelling irradiances measured at 12:00 h during the oxygen flux measurements. The cosine-corrected collector and sensors were programmed to scan from 300 to $700 \mathrm{~nm}$ in $2 \mathrm{~nm}$ intervals. The instrument was deployed at $1.0 \mathrm{~m}$ depth alongside the multichambered respirometer and recorded ambient spectral irradiance hourly. For each measurement 3 scans were taken and the mean reported in units of

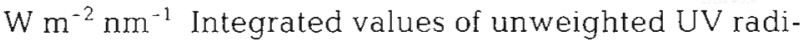
ation (300 to $400 \mathrm{~nm}$ ) and UV-B radiation (300 to $320 \mathrm{~nm}$ ) were calculated, and biologically effective irradiances were determined using the DNA weighting function of Setlow (1974), the generalized plant function of Caldwell (1971), the chloroplast photoinhibition function of Jones \& Kok (1966), and the dinoflagellate photoinhibition weighting function of Cullen et al. (1992).

Construction of the action spectrum. In addition to the UV transparent quartz lids for each chamber of the respirometer, individual long-band pass filters that progressively excluded UV radiation while keeping visible radiation constant were fitted over the respirometer chambers. The long-band pass filters (Schott, WG series) were $16.5 \mathrm{~cm}$ square and $3.0 \mathrm{~mm}$ thick with a nominal cutoff $(50 \%)$ at $280,295,305,320$, 
375 , and $395 \mathrm{~nm}$. The action spectra resulting from this polychromatic approach (Caldwell et al. 1986) are more ecologically relevant when examining UVinduced inhibition of photosynthesis, since photoinhibition is the net result of damage and repair processes (Lesser et al. 1994) whereas repair processes are often dependent on the presence of visible radiation. The action spectrum (biological weighting function) for Pocillopora damicornis was constructed initially by modeling net photosynthesis to irradiance $(P-I)$ to characterize photoinhibition by UV radiation for each filter treatment. Initial plots of the raw data showed no sensitivity to irradiances greater than saturation, as is commonly observed in phytoplankton. Consequently, the hyperbolic tangent $P$ - $I$ model $\left[P_{i}^{\mathrm{B}}=P_{s}^{\mathrm{B}} \tanh \left(\alpha I / P_{s}^{\mathrm{B}}\right)\right]$ of Jassby \& Platt (1976), where $P_{i}^{B}$ ( $\mu$ mol $O_{2}{\mu g^{-1}}^{-1}$ chl a $\mathrm{h}^{-1}$ ) is the instantaneous rate of photosynthesis normalized to chl $a$ at irradiance $i_{;} P_{s}{ }^{B}\left(\mu\right.$ mol $\left.\mathrm{O}_{2}{\mu g^{-1}} \mathrm{chl} \mathrm{a} \mathrm{h}^{-1}\right)$ is the maximum rate of photosynthesis; and $\alpha\left[\mu \mathrm{mol} \mathrm{O}_{2}\right.$ $\mu \mathrm{g}^{-1} \mathrm{chl} \mathrm{a \textrm {h } ^ { - 1 }}$ ( $\mu$ mol quanta $\left.\mathrm{m}^{-2} \mathrm{~s}^{-1}\right)^{-1}$ ) is the initial slope of the P-I curve, was used to non-linearly fit the oxygen flux data normalized to chl $a$ and derive the maximum photosynthetic capacity, $P_{\max }\left(\mu \mathrm{mol} \mathrm{O}_{2}{\mu \mathrm{g}^{-1}} \mathrm{chl} \mathrm{a} \mathrm{h}^{-1}\right.$ ). for each coral.

The $P_{\max }$ data and maximum irradiance of total UV radiation were then used to obtain the differential UV irradiance between successive filters and the differential biological response (photoinhibition) as described by Rundel (1983) to obtain the average action spectrum for each WG filter. Using this approach it is possible to associate the observed fractional changes in photosynthesis with the corresponding change in UV irradiance. These data were then interpolated from 280 to $400 \mathrm{~nm}$ at $1 \mathrm{~nm}$ intervals, normalized to 1 at $290 \mathrm{~nm}$, and then iteratively fit to the exponential equation $\varepsilon(\lambda)=\exp \left(a_{0}+a_{1} \lambda+a_{2} \lambda^{2}\right)$ as described in Rundel (1983). The action spectrum for Pocillopora damicornis was then compared to those for natural assemblages of phytoplankton from Lake Bonney and McMurdo Sound, Antarctica (Neale et al. 1994), cultured Prorocentrum micans acclimated with artificial UV radiation (Lesser 1996a), cultured Phaeodactylum sp. acclimated without UV radiation (Cullen et al. 1992), and cultured zooxanthellae from the sea anemone Aiptasia pallida (Symbiodinium bermudense) acclimated with artificial UV radiation (Lesser 1996b).

\section{RESULTS}

\section{Ambient spectral data}

Unweighted and biologically weighted UV irradiances for Pocillopora damicornis are reported in Table
Table 1. Unweighted and biologically weighted UV irradiance ( $\mathrm{W} \mathrm{m} 2,300$ to $400 \mathrm{~nm}$ ) and UV-B irradiance ( $\mathrm{W} \mathrm{m} \mathrm{m}^{-2}$ 300 to $320 \mathrm{~nm}$ ) for samples of Pocillopora damicornis and Symbiodinium bermudense (Lesser 1996b). Values in parentheses are the percentage of unweighted UV composed of $U V-B$ radiation

\begin{tabular}{|lcc|}
\hline Weighting function & $\begin{array}{r}\text { Pocillopora } \\
\text { damicornis }\end{array}$ & $\begin{array}{c}\text { Symbiodinium } \\
\text { bermudense }\end{array}$ \\
\hline DNA & 0.0044 & 0.00057 \\
Plant & 0.0632 & 0.00503 \\
Photoinhibition (chloroplast) & 6.439 & 0.06757 \\
Photoinhibition (dinoflagellate) & 1.193 & 0.01252 \\
Unweighted UV-B & $1.969(4.32 \%)$ & $0.088(34.38 \%)$ \\
Unweighted UV & 45.55 & 0.256 \\
PAR & 431.0 & 27.13 \\
PAR:UV-B & 219 & 308 \\
& & \\
\hline
\end{tabular}

1 and compared to irradiances measured in a laboratory experiment with cultured zooxanthellae from the sea anemone Aiptasia pallida (Lesser 1996b). The maximum PAR irradiance for $P$. damicornis, measured during the deployment of the respirometers, was $1950 \mu \mathrm{mol}$ quanta $\mathrm{m}^{-2} \mathrm{~s}^{-1}$ and $125 \mu \mathrm{mol}$ quanta $\mathrm{m}^{-2} \mathrm{~s}^{-1}$ for Symbiodinium bermudense (Lesser 1996b).

\section{Spectral data within the respirometer chambers}

UV irradiance in each chamber was determined from transmission spectra taken on both the UV transparent quartz lids and long-band pass filter used for the polychromatic action spectrum measurements. The specific transmission spectral scan for each lid and filter combination were multiplied by the ambient UV spectral irradiance scan at noon and integrated as reported for ambient irradiances in Table 1 to obtain the maximum UV irradiance in each chamber (Table 2). These irradiances include the total amount of UV in each chamber regardless of the standard nominal cutoff of the long-band pass filter. That is, wave-

Table 2. Maximum UV ( $\mathrm{W} \mathrm{m}^{-2}, 300$ to $400 \mathrm{~nm}$ ) and UV-B irradiance ( $\mathrm{W} \mathrm{m} \mathrm{m}^{-2}, 300$ to $320 \mathrm{~nm}$ ) reaching the coral samples inside each chamber during the action spectrum measurement on Pocillopora damicornis

\begin{tabular}{|ccc|}
\hline $\begin{array}{c}\text { WG long-band pass } \\
\text { filter }(50 \% \text { cutoff })\end{array}$ & $\begin{array}{c}\text { UV } \\
\text { irradiance }\end{array}$ & $\begin{array}{c}\text { UV-B } \\
\text { irradiance }\end{array}$ \\
\hline $280 \mathrm{~nm}$ & 39.17 & 1.693 \\
$295 \mathrm{~nm}$ & 38.92 & 1.683 \\
$305 \mathrm{~nm}$ & 38.12 & 1.681 \\
$320 \mathrm{~nm}$ & 37.20 & 1.601 \\
$375 \mathrm{~nm}$ & 24.06 & 0 \\
$395 \mathrm{~nm}$ & 13.18 & 0 \\
\hline
\end{tabular}


lengths below the nominal cutoff for defining these filters $(50 \%)$ are included. Incremental doses of UV radi-

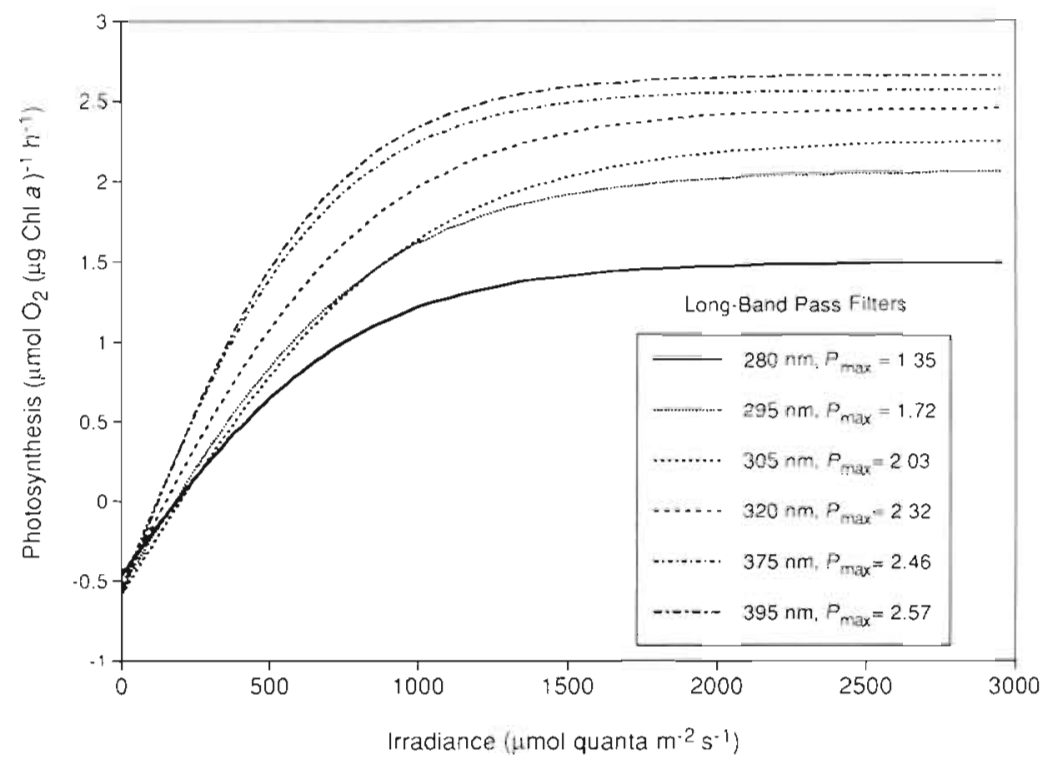

Fig. 1. Photosynthesis-irradiance fits and $P_{\max }$ values ( $\mu$ mol $\mathrm{O}_{2} \mu^{-1} \mathrm{chl} a \mathrm{~h}^{-1}$ ) using the hyperbolic-tangent model on chlorophyll-specific photosynthetic rates of Pocillopora damicornis for each WG long-band pass filter

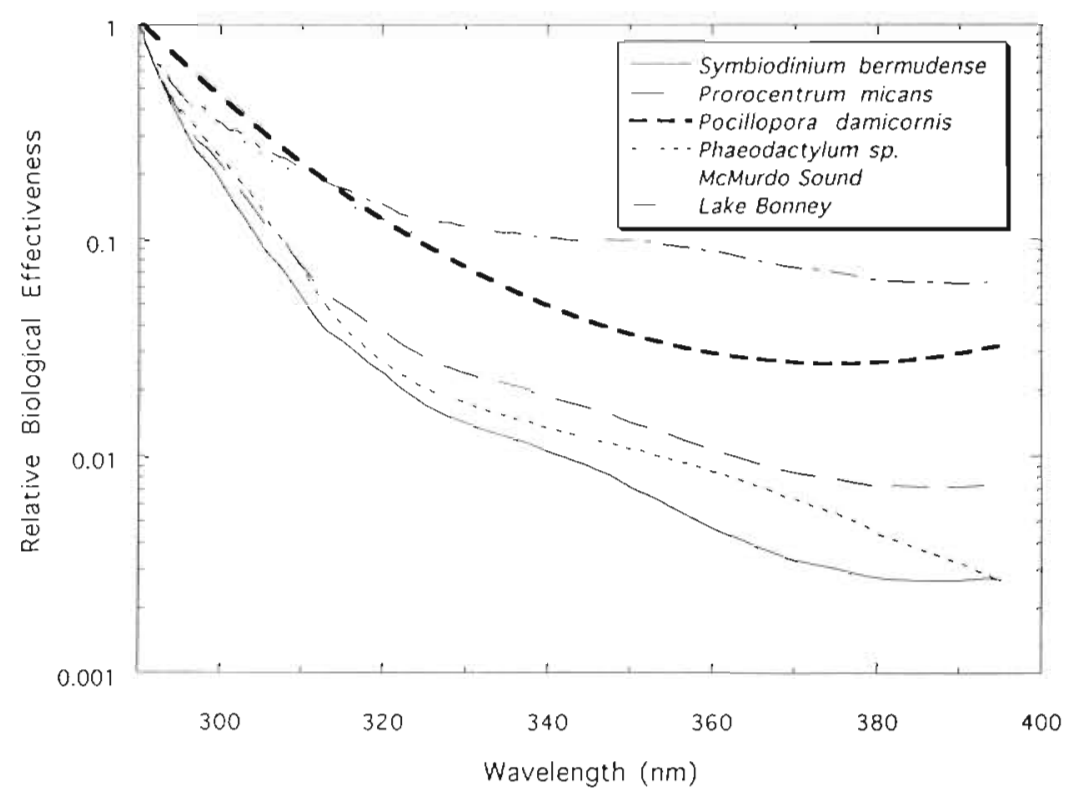

Fig. 2. Comparison of published action spectra (biological weighting functions) to the action spectrum for Pocillopora damicornis. All action spectra were normalized to 1 at $290 \mathrm{~nm}$ for comparison. The action spectra are from natural assemblages of phytoplankton from Lake Bonney and McMurdo Sound, Antarctica (Neale et al. 1994), cultured Prorocentrum micans acclimated with artificial UV radiation (Lesser 1996a), cultured Phaeodactylum sp acclimated without UV radiation (Cullen et al. 1992), and cultured zooxanthellae (Symbiodinium bermudense) from the sea anemone Aiptasia pallida acclimated with artificial UV radiation (Lesser 1996b) ation reported for the 280 and $295 \mathrm{~nm}$ WG filter treatments are the result of the different spectral characteristics of the lid and filter combinations between these 2 treatments and not because there is more ambient UV radiation between 280 and $295 \mathrm{~nm}$ Because of the variability in the spectral characteristics of the chamber lids and filters, the UV irradiance for these filter treatments increases even though the lower limit that the spectroradiometer measures is $300 \mathrm{~nm}$ These differences are small (Table 2) but apparently biologically effective, as observed in the P-I data.

\section{Action spectrum for inhibition of photosynthesis by UV radiation}

Over 200 points of photosynthesis and irradiance were used to obtain each estimate of $P_{\max }$ from the $P-I$ curves (Fig. 1) representing the WG filter treatments all of which had highly significant fits $\left(r^{2}>0.95\right.$ for all curves). These estimates of $P_{\max }$ showed a significant effect of UV radiation (ANOVA, p $<0.05$ ) and all post hoc pairwise comparisons (Student-Neuman-Keuls, SNK) of $P_{\max }$ among filter treatments were significantly $(p<0.05)$ different from one another (Fig. 1), except for the comparison between the 280 and $295 \mathrm{~nm}$ treatment (SNK, p > 0.05) The parameter values for the action spectrum (Fig. 2) derived using the exponential equation $\varepsilon(\lambda)=\exp \left(a_{0}\right.$ $+a_{1} \lambda+a_{2} \lambda^{2}$ ) from Rundel (1983) were $a_{0}=67.538, a_{1}=-0.3793 \mathrm{~nm}^{-1}, a_{2}=$ $5.055 \times 10^{-4} \mathrm{~nm}^{-2}, \mathrm{r}^{2}=0.968$. A $\chi^{2}$ analysis showed no significant difference between the measured and predicted values of biological effectiveness. Action spectra for assemblages of phytoplankton from Antarctica and Pocillopora damicornis show greater wavelength-dependent UV radiation effects compared to action spectra from laboratory acclimated cultures of phytoplankton and zooanthellae (Fig. 2) and, for P. damicornis in particular, an increased effect of UV radiation on photosynthesis between 290 and $310 \mathrm{~nm}$ (Fig. 2) 


\section{DISCUSSION}

Despite the accumulation of significant concentrations of UV absorbing compounds in Pocillopora damicornis (Jokiel et al. in press), samples taken from shallow $(1 \mathrm{~m})$ water show greater wavelength-dependent effects of UV-B radiation on photosynthesis than have been observed for cultured and natural assemblages of marine microalgae. The results of this study contradict the notion that the effects of UV radiation on photosynthesis in $P$. damicornis at $1 \mathrm{~m}$ depth would be less than those on free-living phytoplankton because corals contain higher protein-specific concentrations of MAAs. One reason for this result is the higher biologically effective doses of UV-B radiation received in shallow tropical waters which may be more damaging than previous data has suggested; further, this result allows us to predict that subsequent increases in UV-B radiation, due to even small incremental decreases in stratospheric ozone, may have demonstrable effects on the productivity of this shallow-water coral and possibly other species. The potential for changes in the community structure of shallow reefs dominated by hermatypic corals as a result of increases in UV radiation is unknown.

Action spectra for photosynthesis determined for assemblages of phytoplankton and Pocillopora damicornis, after exposure to natural solar radiation, also show greater wavelength-dependent UV radiation effects in the UV-B portion of the spectrum compared to action spectra from laboratory acclimated cultures of zooxanthellae and phytoplankton. The action spectrum of $P$. damicornis in particular reveals an increased sensitivity between 290 and $310 \mathrm{~nm}$, suggesting that any increase in UV-B radiation due to ozone depletion is likely to have an effect on photosynthesis in this coral. The decrease in sensitivity at, and above, $310 \mathrm{~nm}$ corresponds with the increased absorption of UV radiation by MAAs that absorb principally in the UV-A portion of the spectrum. Comparing these resuits with an action spectrum for the cultured zooxanthellae (Symbiodinium bermudense) of the sea anemone Aiptasia pallida shows that cultured zooxanthellae exhibit significantly lower overall sensitivity to UV radiation (Fig 2). These differences occur despite the fact that the tissues of $P$. damicornis contain 75 times the protein-specific concentration of the MAA shinorine, and 4 times the concentration of mycosporine-glycine as well as 4 additional MAAs not detected in $S$. bermudense (Jokiel et al. in press). There are, however, important differences in the irradiance of total UV and UV-B radiation, and the PAR:UV-B ratio. The ratio of wavelengths involved in activating repair (PAR) and initiating damage (UV-B) is known to be an important factor in offsetting any deleterious effects of UV radiation. The PAR:UV-B ratio is higher for $S$. bermudense than for P. damicornis, and the total biologically effective UV irradiance is lower for $S$. bermudense.

Using the action spectrum for Pocillopora damicornis and the spectral irradiance of noontime solar UV radiation at $1 \mathrm{~m}$ depth on Point Reef (Fig. 3), the integrated biologically effective (weighted) irradiance is $2.036 \mathrm{~W}$ $\mathrm{m}^{-2},(300$ to $400 \mathrm{~nm})$. This effective dose is almost twice that reported in Table 1 for the dinoflagellate action spectrum of Cullen et al. (1992), and is an underestimate as it does not include spectral irradiance below $300 \mathrm{~nm}$. Although more difficult to obtain, action spectra derived from measurements taken during exposure to solar radiation are more ecologically realistic. Laboratory conditions, despite the enhanced UV-B component, may actually underestimate the biological effectiveness of UV radiation in the field, but can still provide important insight into mechanisms of damage caused by UV radiation. More research will be required to determine if a single action spectrum can be used for corals under different spectral irradiances and composition; however, there is already some evidence to suggest that deeper corals exhibit greater sensitivity than their shallow-water conspecifics (Shick et al. 1995). Additionally, the genetic composition of the host (Benzie et al. 1995) and the symbionts (Rowan \& Knowlton 1995) will also contribute to the variability of action spectra within and between species. 
For coral reefs at higher latitudes (e.g. Bermuda) subjected to higher predicted decreases in stratospheric ozone, and for subtropical and tropical reefs periodically exposed to doldrum conditions and increased water clarity which result in a decreased attenuation of UV radiation, the increased sensitivity of corals to UV-B radiation is particularly relevant as UV radiation has been implicated in coral bleaching (Lesser et al. 1990, Gleason \& Wellington 1993). A recent model (Garcia-Pichel 1994) suggests that the functional aspects of accumulating MAAs may be determined by the optical pathlengths, on the order of microns, for free-living photoautotrophs and the probabilities of a photon of UV radiation interacting with a target molecule versus a molecule of MAA. For symbiotic dinoflagellates in corals and other invertebrates the optical pathlengths should be much longer, and presumably result in an increase in the absorbance of UV radiation by MAAs. Although this bio-optical model has been empirically tested, it appears that high concentrations of MAAs and the optical properties of the host tissues of corals may not provide sufficient protection against UV-B radiation below $310 \mathrm{~nm}$ or those wavelengths that will be most affected by any decrease of stratospheric ozone over equatorial regions. Another effect of higher doses of UV radiation is that MAA synthesis and photosynthesis are coupled through the shikimic acid pathway (Bentley 1990). Any inhibition of photosynthesis by an increase in UV radiation may effect carbon flux through the shikimic acid pathway and result in still lower concentrations of MAAs and an increase in the biological effectiveness of UV radiation for corals.

Acknowledgements. We thank Paul Jokiel for his friendship, encouragement, and example as a colleague and innovative leader in the area of UV radiation photobiology of corals. Supported by a grant from the National Science Foundation (OCE-9216307/OCE-9496082) to M.P.L. and the Hawail Institute of Marine Biology through the Edwin Pauley Foundation.

\section{LITERATURE CITED}

Bentley R (1990) The shikimate pathway-a metabolic tree with many branches. Crit Rev Biochem Mol Biol 25: 307-384

Benzie JAH, Haskell A, Lehman H (1995) Variation in the genetic composition of coral (Pocillopora damicornis and Acropora palifera) populations from different reef habitats. Mar Biol 121:731-739

Caldwell MM (1971) Solar ultraviolet radiation and the growth and development of higher plants. In: Giese AC (ed) Photophysiology. Academic Press, New York, p $131-177$

Caldwell MM, Camp LB, Warner CW, Flint SD (1986) Action spectra and their key role in assessing biological consequences of solar UV-B radiation change. In: Worrest RC, Caldwell MM (eds) Stratospheric ozone reduction, solar ultraviolet radiation and plant life. Spnnger-Verlag, New York, p 87-111

Coohill TP (1989) Ultraviolet action spectra (280 to $380 \mathrm{~nm}$ ) and solar effectiveness spectra for higher plants. Photochem Photobiol 50:451-457

Cullen JJ, Neale PJ, Lesser MP (1992) Biological weighting function for the inhibition of phytoplankton photosynthesis by ultraviolet radiation. Science 258:646-651

Cutchis $\mathrm{P}$ (1982) A formula for comparing annual damaging ultraviolet (DUV) radiation doses at tropical and mid-latitude sites. In: Calkins J (ed) The role of solar ultraviolet radiation in marine ecosystems. Plenum Press, New York, p 213-228

Dunlap WC, Chalker BE (1986) Identification and quantitation of near-UV absorbing compounds (S-320) in a hermatypic scleractinian. Coral Reefs 5:153-159

Dunlap WC, Chalker BE, Oliver JK (1986) Bathymetric adaptations of reef-building corals at Davies Reef, Great Barrier Reef, Australia. III. UV-B absorbing compounds. J Exp Mar Biol Ecol 104:239-248

Fleischmann EM (1989) The measurement and penetration of ultraviolet radiation into tropical marine water. Limnol Oceanogr 34:1623-1.629

Frederick JE, Snell HE, Haywood EK (1989) Solar ultraviolet radiation at the earth's surface. Photochem Photobiol 50: $443-450$

Garcia-Pichel F (1994) A model for internal self-shading in planktonic organisms and its implications for the usefulness of ultraviolet screens. Limnol Oceanogr 39: $1704-1717$

Gleason DF (1993) Differential effects of ultraviolet radiation on green and brown morphs of the Caribbean coral Porites astreoides. Limnol Oceanogr 38:1452-1463

Gleason DF, Wellington GM (1993) Ultraviolet radiation and coral bleaching. Nature 365:836-838

Glynn PW, Imai R, Sakai K, Nakano Y, Yamazato K (1992) Experimental responses of Okinawan (Ryukyu Islands, Japan] reef corals to high sea temperature and UV radiation. In: Richmond R (ed) Proc 7 th Int Symp Coral Reef, Guam. University of Guam, p 27-37

Green AES, Sawada T, Shettle EP (1974) The middle ultraviolet reaching the ground. Photochem Photobiol 19: $251-259$

Halldal P (1968) Photosynthetic capacities and photosynthetic action spectra of endozoic algae of the massive coral Favia. Biol Bull 134:411-424

Jassby AD, Platt T (1976) Mathematical formulation of the relationship between photosynthesis and light for phytoplankton. Limnol Oceanogr 21:540-547

Jeffrey SW, Humphrey GF (1975) New spectrophotometric equations for determining chlorophylls $a, b, c$, and $c_{2}$ in higher plants, algae and natural phytoplankton. Biochem Physiol Pflanz 167:191-194

Jerlov NG (1950) Ultra-violet radiation in the sea. Nature 116: $111-112$

Jokiel PL (1980) Solar ultraviolet radiation and coral reef epifauna. Sclence 207:1069-1071

Jokiel PL, Lesser MP, Ondrusek M (in press) UV-absorbing compounds in the coral Pocillopora damicornis: the effects of water flow, irradiance, and UV radiation. Limnol Oceanogr

Jokiel PL, York RH Jr (1982) Solar ultraviolet photobiology of the reef coral Pocillopora damicornis and symbiotic zooxanthellae. Bull Mar Sci 32:301-315

Jokiel PL, York RH Jr (1984) Importance of ultraviolet radiation in photoinhibition of microalgal growth. Limnol Oceanogr 29:192-199 
Jones LW, Kok B (1966) Photoinhibition of chloroplast reactions. I. Kinetics and action spectra. Plant Physiol 41: $1037-1043$

Kinzie RA III (1993) Effects of ambient levels of solar ultraviolet radiation on zooxanthellae and photosynthesis of the reef coral Montipora verrucosa. Mar Biol 116:319-327

Lesser MP (1996a) Acclimation of phytoplankton to UV-B radiation: oxidative stress and photoinhibition of photosynthesis are not prevented by UV absorbing compounds in the dinoflagellate Prorocentrum micans. Mar Ecol Prog Ser 132:287-297

Lesser MP (1996b) Exposure of symbiotic dinoflagellates to elevated temperatures and ultraviolet radiation causes oxidative stress and inhibits photosynthesis. Limnol Oceanogr in press

Lesser MP, Cullen JJ, Neale PJ (1994) Photoinhibition of photosynthesis in the marine diatom Thalassiosira pseudonana during acute exposure to utraviolet $\mathrm{B}$ radiation: relative importance of damage and repair. J Phycol 30:183-192

Lesser MP, Shick JM (1989) Effects of irradiance and ultraviolet radiation on photoadaptation in the zooxanthellae of Aiptasia pallida: primary production, photoinhibition, and enzymic defenses against oxygen toxicity. Mar Biol 102: 243-255

Lesser MP, Stochaj WR, Tapley DW, Shick JM (1990) Bleaching in coral reef anthozoans: effects of irradiance, ultraviolet radiation, and temperature on the activities of protective enzymes against active oxygen. Coral Reefs 8: $225-232$

Madronich S (1992) Implications of recent total atmospheric ozone measurements for biologically active ultraviolet radiation reaching the earth's surface. Geophys Res Lett 19:37-40

Neale PJ, Lesser MP, Cullen JJ (1994) Effects of ultraviolet

This article was presented by O. Holm-Hansen (Senior

Editorial Advisor), La Jolla, California, USA radiation on the photosynthesis of phytoplankton in the vicinity of McMurdo Station, Antarctica. In: Weiler CS, Penhale PA (eds) Ultraviolet radiation and biological research in Antarctica. American Geophysical Union, Washington, DC, p 125-142

Porter JW, Muscatine L, Dubinsky Z, Falkowski PG (1984) Primary production and photoadaptation in light- and shade-adapted colonies of the symbiotic coral, Stylophora pistillata. Proc R Soc Lond Ser B 222:161-180

Rowan R, Knowlton N (1995) Intraspecific diversity and ecological zonation in coral-algal symbiosis. Proc Natl Acad Sci $92: 2850-2853$

Rundel RD (1983) Action spectra and estimation of biologically effective UV radiation. Physiol Plant 58:360-366

Setlow RB (1974) The wavelengths in sunlight effective in producing skin cancer: a theoretical analysis. Proc Natl Acad Sci USA 71:3363-3366

Shick JM, Lesser MP, Dunlap WC, Stochaj W, Chalker BE, Wu Won J (1995) Depth-dependent responses to solar ultraviolet radiation and oxidative stress in the zooxanthellate coral Acropora microphthalma. Mar Biol 122:41-51

Siebeck O (1988) Experimental investigation of UV tolerance in hermatypic corals (Scleractinia). Mar Ecol Prog Ser 43: $95-103$

Smith RC, Baker KS (1979) Penetration of UV-B and biologically effective dose-rates in natural waters. Photochem Photobiol 29:311-323

Smith RC, Baker KS, Holm-Hansen O, Olson RS (1980) Photoinhibition of photosynthesis in natural waters, Photochem Photobiol 31:585-592

Stochaj WR, Dunlap WC, Shick JM (1994) Two new UVabsorbing mycosporine-like amino acids from the sea anemone Anthopleura elegantissina and the effects of zooxanthellae and spectral irradiance on chemical composition and content. Mar Biol 118:149-156

Manuscript first received: May 20, 1995

Revised version accepted: November 22, 1995 